\title{
Papéis gerenciais dos diretores dos hospitais públicos de Belo Horizonte
}

\author{
Wânia Candida da Silva
}

Mestre em Administração pela Universidade Federal de Viçosa.

waniacandida@yahoo.com.br

\author{
Nina Rosa da Silveira Cunha \\ Doutora em Economia Aplicada pela Universidade Federal de Viçosa \\ ninarosa@ufv.br
}

\section{Flávio Diniz Capanema}

Doutor em Ciências da Saúde pela UFMG e Coordenador do Núcleo de Inovações Tecnológicas/ Diretoria de Gestão de Pessoas da Fundação Hospitalar do Estado de Minas Gerais.

flavio.capanema@fhemig.mg.gov.br

\author{
Afonso Augusto Teixeira de Freitas de Carvalho Lima \\ Doutor em Engenharia de Produção pela Universidade Federal de Santa Catarina. \\ afonsoli@ufv.br
}

RESUMO: O mapeamento dos papéis gerenciais que os gestores dos hospitais desempenham é uma forma de identificar o que esses profissionais consideram como essencial para o desenvolvimento das atribuições do cargo. O objetivo geral do trabalho foi identificar os papéis gerenciais esperados dos gestores dos hospitais públicos de Belo Horizonte. A amostra foi composta de 13 diretores de hospitais. Foi utilizada a técnica de análise de conteúdo das entrevistas e os papéis gerenciais foram analisados com base no Modelo de Quinn. Os resultados indicam que o papel político e o papel diretor foram os mais ressaltados pelos entrevistados. O conhecimento da administração pública e a capacidade de articulação política constituem o papel político e devem estar presentes na figura do diretor hospitalar. O destaque do papel diretor reflete a adoção do modelo de gestão pautado na busca pela eficiência a partir da definição de metas e objetivos. A principal contribuição deste trabalho foi diagnosticar que o modelo de Quinn mostrou-se incompleto diante da realidade dos hospitais públicos de Minas Gerais. Desta forma, o papel político representa a adequação do modelo à realidade estudada.

PALAVRAS-CHAVE: Gestão Hospitalar. Papéis Gerenciais. Administração Pública.

\section{Management roles of the directors of the public hospitals in Belo Horizonte}

ABSTRACT: The mapping of the management roles that hospital managers perform is a way to identify what these professionals consider as essential for their assignments development. The general objective of this research was to identify the expected management roles of public hospitals managers in Belo Horizonte. The sample was composed by 13 hospital directors. The interview content analysis technique was utilized and the management roles were analyzed through the Quinn's model. The results indicate that the political role and the directing role were the most emphasized of all by the interviewed. The knowledge of public administration and the capability for political articulation constitute the political role and must be present in the figure of the hospital director. The highlight of the directing role mirrors the adoption of the management model guided by the search of efficiency from the definition of goals and objectives. The main contribution of this research was the diagnosis that the Quinn's model is incomplete vis-à-vis the reality of the Minas Gerais public hospitals, thus, the political role represents the adaptation of the model to the studied reality.

KEY WORDS: Hospital Management, Management Roles, Public Administration.

1 Submetido em 28 de Maio de 2012. Aceito em 03 de Dezembro de 2012. 0 artigo foi avaliado segundo o processo de duplo anonimato além de ser avaliado pelo editor. Editores responsáveis: Márcio Augusto Gonçalves e Lucas Maia dos Santos. Reprodução parcial ou total de trabalhos derivativos permitidos com a citação apropriada da fonte. 


\section{INTRODUÇÃO}

O sistema de saúde no Brasil tem passado por constantes cobranças e críticas ao longo de toda a sua história. Os hospitais públicos vivenciam a discrepância que há entre o conjunto de problemas e a capacidade do Estado em resolvê-los, sendo considerados instituições reconhecidamente ineficientes e ineficazes pela maior parte da sociedade brasileira (ACURCIO, 2005).

Novos processos para adequação e transformação das organizações públicas, visando atender a alguns condicionantes para que se estabeleça a gestão eficiente, eficaz e efetiva se fazem necessários. Nesse cenário, verifica-se a necessidade de os hospitais públicos também se adaptarem à nova realidade. Portanto, a capacidade de responder aos anseios da sociedade depende, em parte, da valorização dos conhecimentos dos gestores hospitalares, visto que eles desempenham funções-chave nessas organizações. Na maioria das vezes, os gestores são responsabilizados pela ineficiência e ineficácia da instituição. Segundo Moretto Neto, Silva e Schimitt (2007), a ampliação dos problemas administrativos e a complexidade da gestão hospitalar imprimem a necessidade de uma administração profissional, realizada por pessoas preparadas para a administração dos negócios do hospital.

Assim, o mapeamento dos papéis gerenciais que os gestores dos hospitais públicos desempenham é uma maneira de identificar o que esses profissionais consideram essencial para o desenvolvimento das atribuições do cargo, tendo como alicerce o próprio ambiente de trabalho e as experiências pessoais. Nesse sentido, o objetivo geral deste estudo é o de detectar os papéis gerenciais esperados dos gestores dos hospitais públicos de Belo Horizonte.

\section{MODELO DE QUINN}

O modelo utilizado nesta pesquisa foi escolhido após análise da literatura de competências e papéis gerenciais, tendo como foco o modelo gerencial proposto por Quinn (1988). A escolha deu-se em razão do modelo apresentar de forma coerente os modelos de gestão associados a papéis gerenciais, com grande amplitude na definição das competências gerenciais. Picchiai (2008, p. 8) enfatiza que as pesquisas realizadas por Quinn revelam que "o fato de o indivíduo compreender e apreciar cada um dos quatro modelos sugere que ele aprendeu algo no âmbito organizacional e aprofundou sua complexidade cognitiva no tocante à liderança gerencial". Dessa forma, os papéis gerenciais devem ser entendidos a partir dos quatro modelos de gestão e dão origem a 24 competências gerenciais, conforme a Figura 1.

Os oito papéis antagônicos do modelo de Quinn permitem refletir sobre a necessidade dos gerentes em desenvolverem habilidades associadas a papéis conflitantes. Para tornar-se um gerente capaz, é preciso mais do que desenvolver as competências; tem-se que agir diante de determinada situação, enxergar as características contrastantes, mesclar e equilibrar os diferentes papéis. A seguir são apresentados os oito papéis gerenciais correspondentes a cada modelo proposto por Quinn (1988). Os conceitos apresentados nesta seção estão baseados em Quinn et al. (2003).

\section{Papel mentor}

Caracteriza-se pela ênfase no desenvolvimento das pessoas a partir de uma dedicação cuidadosa e empática. O gerente deve ser atencioso, acessível aos demais funcionários, prestativo e justo, além de contribuir e proporcionar o aprimoramento de competências e o desenvolvimento individual dos empregados.

\section{Papel facilitador}

O papel facilitador encontra-se também no modelo das relações humanas. Tem-se na função de facilitador um gerente que alimente os esforços coletivos, crie a coesão e o trabalho em equipe e administre os conflitos.

\section{Papel monitor}

Espera-se que o gerente tenha conhecimento das coisas que acontecem em sua unidade, com o objetivo de averiguar se as pessoas estão cumprindo as regras e se o setor está desempenhado a sua parte. O monitor é um bom analista e domina os fatos e seus detalhes. Entre as características desse papel, destacam-se o gosto por dados, a análise de informações rotineiras de inspeção e vistoria e a revisão de relatórios. 
Figura 1. Competências e papéis dos líderes a partir dos quatro modelos de gestão.

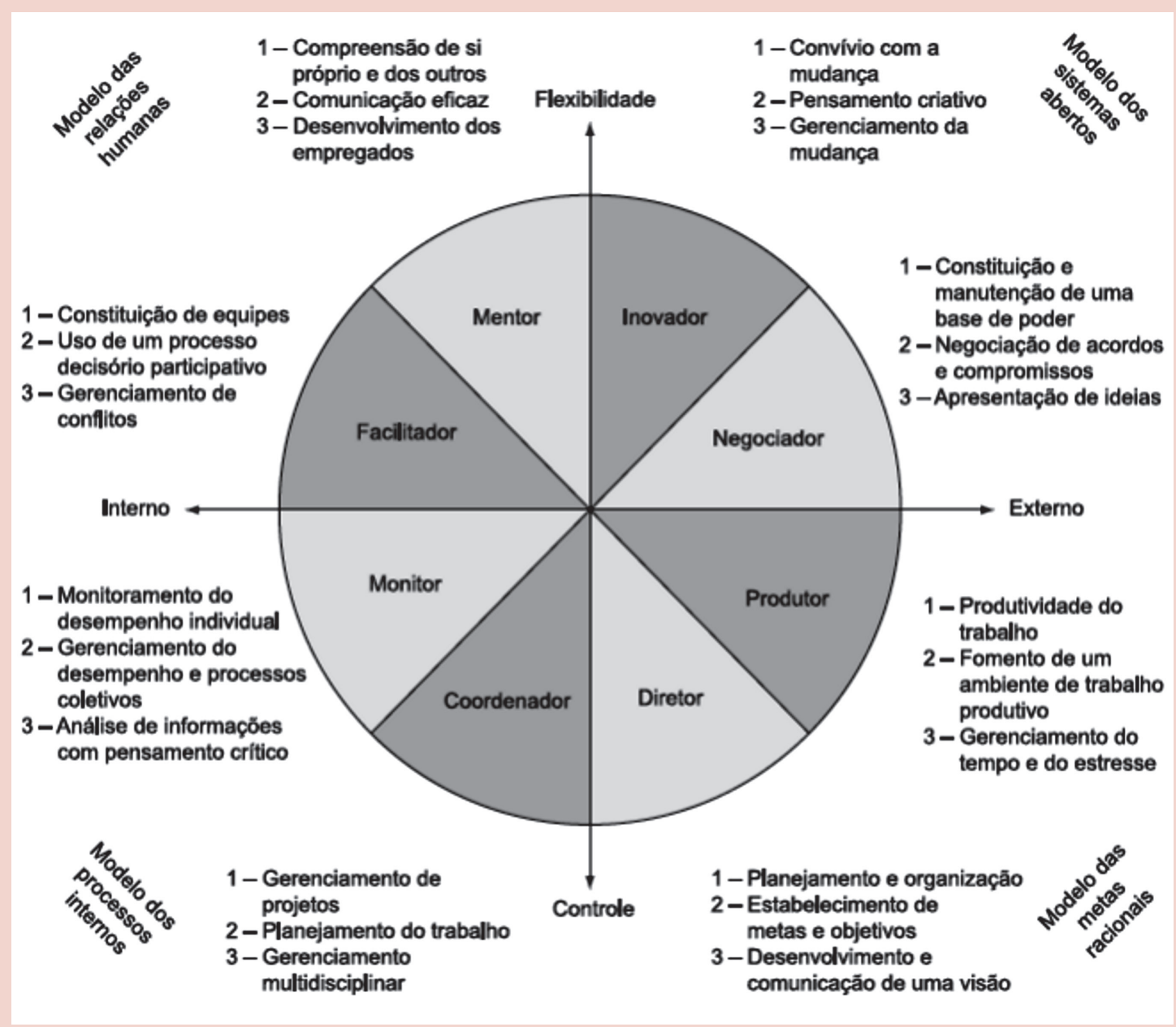

Fonte: Adaptada de Quinn et al. (2003, p. 17).

\section{Papel coordenador}

No papel de coordenador o gerente deve dar sustentação e estruturação ao fluxo do sistema, além disso, deve ser um profissional digno de confiança e crédito. Entre os traços comportamentais desse gerente, destaca-se a coordenação de esforços da equipe, enfrentamento e resolução de problemas de ordem tecnológica, logística e doméstica.

\section{Papel diretor}

Nesse é esperado que o gerente explicite as expectativas por meio de processos e seja um deflagrador decisivo.

\section{Papel produtor}

Também no quadrante do modelo das metas racionais, o gerente no papel produtor deve orientar-se para tarefas, com foco no trabalho e demonstrando interesse, motivação e ímpeto pessoal.

\section{Papel negociador}

Inserido no modelo dos sistemas abertos, o papel negociador tem como característica a preocupação com a sustentação da legitimidade exterior e a obtenção de recursos externos. Os gerentes devem apresentar e negociar ideias com eficácia, ter astúcia e cuidar da imagem e da reputação. 


\section{Papel inovador}

O papel inovador encontra-se no modelo dos sistemas abertos. É relacionado às capacidades de adaptação e de resposta ao ambiente externo em constante mudança. Envolve o uso da criatividade, ideias e insights intuitivos. Espera-se que o gerente trabalhe para se precaver diante das mudanças, identificar as tendências significativas, estando sempre atento às transformações do ambiente.

\section{PROCEDIMENTOS METODOLÓGICOS}

O universo da pesquisa foi composto pelos hospitais da rede pública da cidade de Belo Horizonte - Minas Gerais. O estado de Minas Gerais passou, nos últimos anos, por um processo de reforma da administração pública lançado em 2003 pelo governo Aécio Neves, conhecido como "Choque de Gestão". Neste sentido, o estudo dos hospitais de Minas Gerais se justifica pela possível averiguação das consequências desse processo na gestão hospitalar. A opção pela cidade de Belo Horizonte teve caráter intencional, devido ao fato da cidade possuir hospitais na esfera municipal, estadual e federal, possibilitando, assim, a realização da pesquisa nas diferentes esferas da administração pública. Além disso, Belo Horizonte tem grande importância no contexto da saúde pública do estado de Minas Gerais.

Para conhecimento da estrutura organizacional dos hospitais e definição dos elementos participantes da pesquisa foram utilizados os organogramas dos hospitais. A definição da amostra seguiu o critério não probabilístico por acessibilidade, segundo qual o pesquisador seleciona os elementos a que tem acesso e admite que, de alguma maneira, representem o universo amostral (MALHOTRA, 2011). Neste estudo foram convidados a participar os diretores dos hospitais públicos de Belo Horizonte e os gerentes de áreas específicas que se encontram diretamente subordinados aos diretores hospitalares.

A Tabela 1 mostra a relação do número de diretores e gerentes selecionados para a pesquisa e o número dos que efetivamente participaram. Observa-se que a pesquisa abordou $87 \%$ dos diretores e $86 \%$ dos gerentes.

TABELA 1. Número de funcionários analisados em cada hospital.

\begin{tabular}{|c|c|c|c|c|}
\hline \multirow[b]{2}{*}{ Hospital } & \multicolumn{2}{|c|}{ Diretor } & \multicolumn{2}{|c|}{ Gerentes } \\
\hline & Total & $\begin{array}{l}\text { Sujeitos da } \\
\text { pesquisa }\end{array}$ & Total & $\begin{array}{c}\text { Sujeitos da } \\
\text { pesquisa }\end{array}$ \\
\hline \multicolumn{5}{|l|}{ Municipal ${ }^{1}$} \\
\hline Hospital Odilon Behrens & 1 & 1 & 5 & 3 \\
\hline \multicolumn{5}{|l|}{ Estadual $^{2}$} \\
\hline Centro Mineiro de Toxicomania & 1 & 1 & 2 & 2 \\
\hline Centro Psíquico da Adolescência e Infância & 1 & 1 & 1 & 1 \\
\hline Hospital Alberto Cavalcanti & 1 & 1 & 3 & 3 \\
\hline Hospital Eduardo de Menezes & 1 & 0 & 2 & 0 \\
\hline Hospital Galba Veloso & 1 & 1 & 2 & 1 \\
\hline Hospital Infantil João Paulo II & 1 & 1 & 2 & 2 \\
\hline Hospital João XXIII & 1 & 1 & 4 & 4 \\
\hline Hospital Júlia Kubitschek & 1 & 1 & 3 & 3 \\
\hline Hospital Maria Amélia Lins & 1 & 1 & 1 & 1 \\
\hline Instituto Raul Soares & 1 & 1 & 2 & 2 \\
\hline Maternidade Odete Valadares & 1 & 1 & 2 & 2 \\
\hline MG Transplantes & 1 & 1 & 1 & 1 \\
\hline \multicolumn{5}{|l|}{ Federal ${ }^{3}$} \\
\hline Hospital das Clínicas da UFMG & 1 & 0 & 3 & 3 \\
\hline Hospital Risoleta Toletino Neves & 1 & 1 & 2 & 2 \\
\hline Total & 15 & 13 & 35 & 30 \\
\hline
\end{tabular}

Fontes:

1 Belo Horizonte (2011).

2 Minas Gerais (2011).

${ }^{3}$ Brasil (2011). 
Quanto aos objetivos, a pesquisa se caracterizou como estudo descrito e exploratório. O modelo, originalmente apresentado anteriormente, foi adaptado para o estudo dos hospitais públicos, pois se anteviu, a partir da prospecção inicial, a necessidade de nele se acrescentar o papel político e as competências, capacidade de articulação política e conhecimento da administração pública, o que se revelou uma decisão correta a partir da análise das verbalizações dos entrevistados (Fig. 2). A pesquisa utilizou como base o Modelo de Quinn (1988).

\section{FIGURA 2. Competências e papéis dos gestores adaptados para os hospitais públicos de Belo Horizonte.}

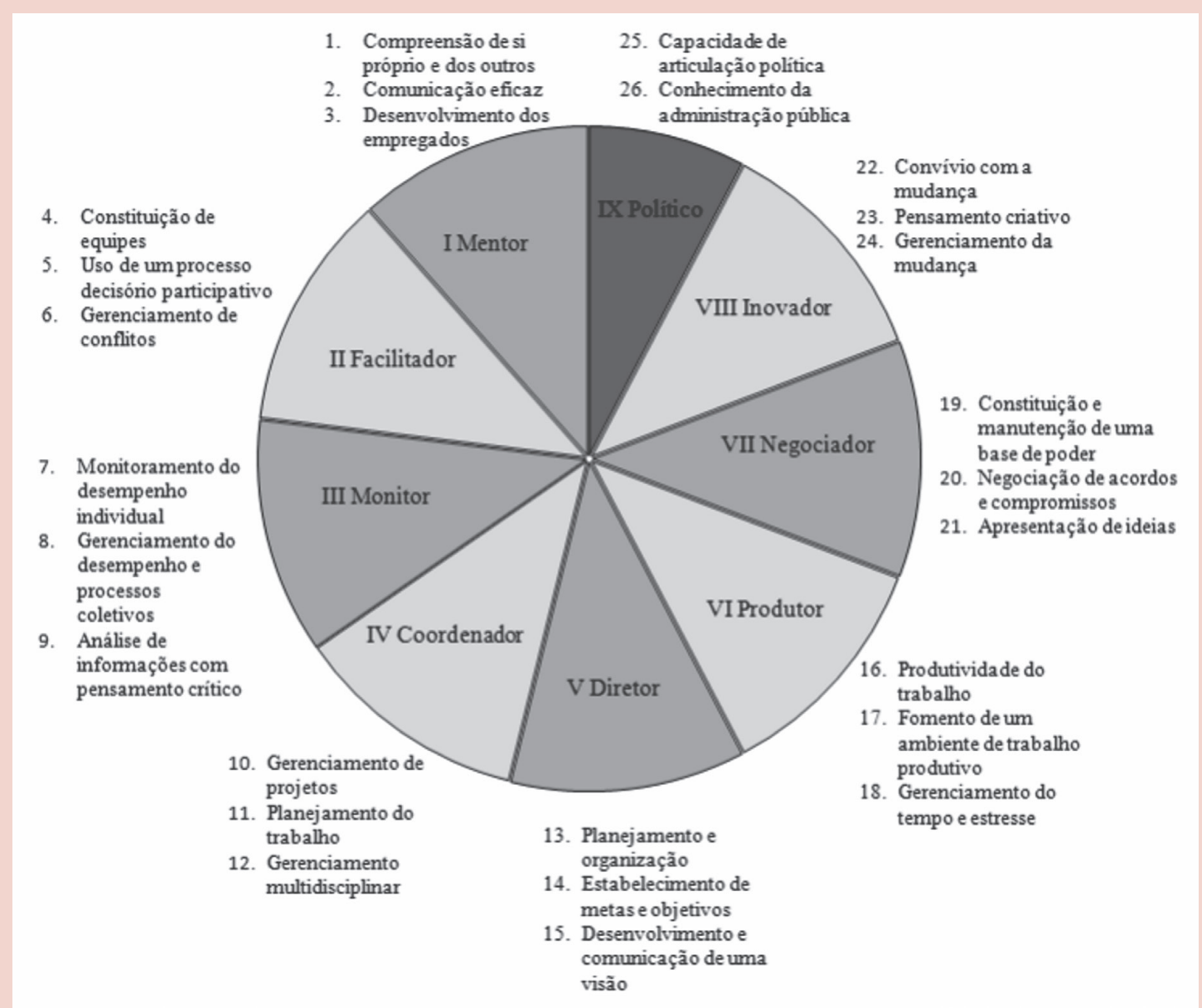

Fonte: Adaptado de Quinn et al. (2003).

A coleta de dados primários foi realizada por meio de entrevistas semiestruturadas com os sujeitos da pesquisa, no período de 10 de fevereiro a 4 de maio de 2012. Neste artigo, foram considerados como sujeitos de pesquisa os diretores dos hospitais a fim de levantar quais papéis gerenciais eles consideravam necessários para um diretor de hospital público.

A pesquisa teve abordagem qualitativa e utilizou-se, para tratamento de dados, a análise de conteúdo, tendo com principal referencial Bardin (2011).

\section{RESULTADOS}

A Tabela 2 apresenta o número de entrevistados que ressaltaram cada papel gerencial. A discussão dos dados apresentados nas tabelas dar-se-á a seguir, de acordo com as categorias analisadas.

\section{Mentor}

O papel mentor, também conhecido como do interesse humano, teve índice de relatos de 44\%, sendo, desta forma, o quinto papel gerencial mais ressaltado pelos diretores. Destacou-se nesse papel a relevância atrelada à comunicação eficaz, citada por $83 \%$ dos entrevistados. 
TABELA 2. Resultado da análise de conteúdo de acordo com as categorias.

\begin{tabular}{lcc}
\multicolumn{1}{c}{ Categorias } & Total absoluto & Total relativo \\
I. Mentor & 16 & $44 \%$ \\
II. Facilitador & 22 & $61 \%$ \\
III. Monitor & 8 & $22 \%$ \\
IV. Coordenador & 21 & $58 \%$ \\
V. Diretor & 23 & $64 \%$ \\
VI. Produtor & 13 & $36 \%$ \\
VII. Negociador & 7 & $19 \%$ \\
VIII. Inovador & 13 & $36 \%$ \\
IX. Político & 22 & $92 \%$
\end{tabular}

Fonte: Resultados da pesquisa, 2012.

\begin{abstract}
A comunicação eficaz e a motivação do funcionário traz essa reestruturação no sentido de se inserir adequadamente dentro do novo projeto (E1).

A clareza na comunicação é fundamental em qualquer organização. É muito mais fácil trabalhar quando você deixa tudo claro (E3).

Então a gente tem que superar todas as dificuldades de comunicação, que é um dos principais problemas hoje, para a gente conseguir fazer a coisa funcionar (E9).
\end{abstract}

A importância desse papel consiste na dedicação cuidadosa do aprimoramento das competências e do desenvolvimento dos empregados, necessários especialmente no setor público.

\title{
II. Facilitador
}

O papel facilitador teve índice de relatos de $61 \%$ durante as entrevistas, sendo o terceiro mais mencionado pelos diretores, considerado relevante em todas os seus desdobramentos.
Eu acho que tem que conseguir trabalhar em equipe. Então tem que trabalhar mais com as pessoas, dividir mais as tarefas, conseguir conversar mais, dialogar mais, chegar a um comum acordo, isso é a capacidade de trabalhar em equipe (E8).
A gente procura ter uma gestão colegiada, de apoio à instituição (E9).
O que eu percebo é que os conflitos surgem dos combinados que não foram cumpridos. Então todos aqueles fluxos, os protocolos, tudo que não está claro para as pessoas. Então é ai que surgem os conflitos (E3).

A sua importância se dá pela busca da coesão, alimentando um ambiente de trabalho em equipe na organização hospitalar.

\section{Monitor}

O papel monitor obteve a oitava colocação, atingindo um índice de apenas $22 \%$. Apresentou grande discrepância em relação à importância atribuída a cada competência, sendo que o gerenciamento de desempenho e processos coletivos foi ressaltado por $58 \%$ dos entrevistados, enquanto a análise de informações com pensamento crítico não foi aludida por qualquer entrevistado.

Os processos mais suscetíveis a falhas são aqueles mal combinados, mal divulgados, mal monitorados. Em uma organização que tem os objetivos e fluxos bem definidos e divulgados, a possibilidade de falhas é menor. [...] A gente vê que os setores em que os processos estão bem combinados ocorrem menos falhas e conflitos (E3).

Outro processo que era muito ruim no hospital é o tempo de espera de laboratório, que era uma queixa comum. Então, com as reuniões do colegiado e reuniões internas, o problema foi sanado porque agora todos os resultados são jogados no computador e isso já melhorou (E6). 
A pouca importância atribuída ao papel, bem como a discrepância entre as competências que o compõem, pode significar a falta de monitoramento do cumprimento de regras e das coisas que acontecem no seu setor, bem como o "esquecimento" pela análise de informações.

\title{
IV. Coordenador
}

O papel coordenador foi o quarto papel mais ressaltado pelos diretores, obtendo índice de 58\%.

O maior projeto é o plano diretor que a gente está realmente trabalhando porque ele vai proporcionar uma melhoria muito grande. Então nós estamos precisando melhorar realmente a nossa forma de trabalhar, a estrutura física, os nossos equipamentos e equipes (E3).

Eu punha o funcionário em um serviço menos importante até achar uma função para ele. Daí de repente aparecia uma função que caía igual uma luva, então eu pensava assim: Nossa! Isso é a cara dessa pessoa! E eu acho que quase todos esses funcionários desempenharam extremamente bem a nova função (E2).

Quando você pega a chefia de um hospital inteiro você tem que saber juntar todos os pedaços que o compõem e entender qual a forma de trabalho (E7).

Você tem que fazer com que trabalhem juntos e que a empresa funcione por engrenagem. É preciso ter capacidade de trabalhar com classes diferentes, médico, enfermagem, farmácia, limpeza, então você tem que ter uma música para cada um (E4).

A consistência da relevância atribuída às três competências que integram esse papel demonstra sua importância no desempenho das atribuições do diretor hospitalar.

\section{Diretor}

O papel de diretor foi o mais ressaltado entre os papéis propostos pelo modelo de Quinn, ficando atrás apenas do papel político, o novo papel identificado a partir das análises das entrevistas. O foco no estabelecimento de metas e objetivos e o planejamento e organização são os responsáveis por esse destaque.

\begin{abstract}
Saber dividir o trabalho, compartilhar o trabalho. Você tem que saber respeitar a hierarquia que há dentro da instituição, não passar nunca das chefias imediatas, ponderar essas chefias com os seus subordinados (E5).
\end{abstract}

Então nós trabalhamos com metas físicas e metas de assistência, nós temos que trabalhar com taxa de ocupação, taxa de permanência, taxa de mortalidade, taxa de infecção hospitalar. Todos esses resultados são necessários. [...] A gente tem metas a cumprir. Eu sou avaliado tanto pelo meu chefe quanto pelos meus colaboradores (E10).

Hoje em dia precisa saber também trabalhar com essa questão de resultados, acompanhamento e bater metas. [...] A gente tem um acordo de resultados que a gente discute com a FHEMIG e esse acordo de resultados tem alguns indicadores (E8).

São as exigências da nova administração pública centrada em resultados, em metas e indicadores. A administração geral deixa os objetivos claros, até mesmo para que possamos cumprir essas exigências. [...] Acho fundamental o entendimento da administração por resultados (E1).

Modificamos a questão da missão e da visão, a gente fez um levantamento do que a gente podia oferecer. [...] Ser uma referência estadual [...]. É essa a nossa missão. Então vamos deixar os casos simples de assistência básica e nós vamos atender aos estágios secundários e terciários (E7).

Esse resultado reflete a adoção de um novo modelo de gestão pela administração pública, pautado pela busca da eficiência a partir da definição de metas e objetivos.

\section{Produtor}

O papel produtor obteve índice de relatos de $36 \%$ dos entrevistados. Nesse papel enfatiza-se a pouca importância atribuída ao gerenciamento do tempo e do estresse. 
Temos avaliação das pessoas, porque a meta é clara, definida e compactuada. Tudo isso é colocado ao funcionário quando ele chega ao hospital, ele não é livre para fazer o que quer, ele tem que prestar contas (E6).

A gente tem o acordo de resultados que é avaliado a cada três meses e o resultado desse acordo influencia em uma gratificação que a gente recebe todo mês, quer dizer, se eu trabalhar junto com a minha equipe, pra gente atingir esses objetivos, a gente vai ter uma gratificação melhor, se a gente avacalhar com a equipe e não atingir os objetivos a gente vai ter uma remuneração menor (E8).

Então eu diria que ter determinação e capacidade de resistir à pressão também são completamente imprescindíveis a qualquer gestor (E2).

Cabe salientar que, apesar da pouca importância atribuída, o papel produtor, bem como as competências que o compõem, é essencial ao desenvolvimento de uma instituição hospitalar pública, principalmente por envolver a busca pela produtividade no trabalho, que é um problema no âmbito atual da administração pública.

\title{
VII. Negociador
}

Esse foi o papel menos citado pelos entrevistados (19\%). A apresentação de ideias como uma competência não foi mencionada por algum entrevistado, além disso, as outras duas competências que compõem esse papel também foram pouco realçadas.

\begin{abstract}
Você tem que ser uma pessoa em que as outras pessoas contem seus conflitos, busquem soluções, que querem apoio. Então você tem que passar confiança para essas pessoas para que elas confiem em você, aceitem suas ideias e te ajudem a cumprir o trabalho (E6).
\end{abstract}

Então a gente consegue discutir isso dentro da equipe quando envolve mais de uma área, envolve transporte, envolve internação, envolve farmácia. Então a gente tem que negociar (E8).

A falta de relevância atribuída ao negociador pode significar esquecimento dos diretores hospitalares em relação à sustentação de sua legitimidade exterior e o cuidado com a imagem e reputação.

\section{Inovador}

O papel inovador teve índice de relatos durante as entrevistas de $36 \%$. Nesse papel sobressaiu-se a discrepância da importância atribuída às competências que o compõem. O convívio com a mudança foi ressaltado por $92 \%$ dos entrevistados, enquanto o pensamento criativo não foi acentuado pelos entrevistados. A importância desse papel se dá pela necessidade de adaptação e resposta ao ambiente externo em constante mudança, principalmente no tocante à administração e à saúde pública.

Eu acho que você tem que estar pronto para sair de onde você está e ir para frente. [...] Se você se acomoda, as coisas ficam muito pesadas para você. O máximo que pode acontecer é eu ter que partir para outra. Isso pesa porque tem todo orgulho e vaidade (E2).

Nada nasce e fica assim, a gente não é assim, a gente nasce, a gente cresce, a gente muda por dentro. A gente não é sempre assim (E7).

Então essa necessidade de mexer no conforto das pessoas é o mais difícil. Tem coisas que eu não posso fazer agora, mas posso ir preparando o caminho para que as pessoas entendam como é que funciona, agora não dá. Então continua fazendo o que é necessário e vai preparando o caminho (E7).

Tem muita resistência ainda das pessoas? Tem, porque muita gente tava acostumado a ser dono do lugar, e o dono que podia fazer tudo, trabalhar o horário que fosse. Essa modernização agora começou a ser mais aceita porque as pessoas estão vendo que tem que funcionar (E9).

\section{Político}

O papel político foi identificado a partir da análise das entrevistas com os diretores. Observou-se que 92\% deles ressaltaram questões relacionadas ao papel político. 
O político, segundo definição de Betioli (1995), é um indivíduo membro de uma polis organizada que tem a função de garantir os direitos e assumir os deveres. O aumento da interação entre sociedade e governantes tem exigido cada vez mais que os gestores públicos desenvolvam efetivamente o papel político, principalmente quanto à garantia do direito da população. A necessidade de uma gestão pública mais acessível à população e que atenda aos interesses públicos exige dos gestores mais articulação com a sociedade.

\begin{abstract}
Questões relacionadas às articulações políticas foram aludidas por 10 diretores. Eles se relacionam constantemente com diversos órgãos das esferas municipal, estadual e federal, por isso é essencial manter bom trâmite político. Além disso, por se tratar de um cargo de confiança, a nomeação dos diretores está diretamente relacionada à forma como eles se posicionam diante das questões políticas. "A gente tem que ter essa governança corporativa com o governo federal, estadual e municipal e também com os outros hospitais" (E1).
\end{abstract}

Ainda, conforme afirmado pelos diretores, as articulações políticas auxiliam na busca de recursos para a instituição e também nas atividades desenvolvidas no dia-a-dia do hospital.

Tem, claro, as outras pessoas que a gente tem contato, por exemplo, pessoas que têm influência política. Hoje estamos prestes a receber verbas do Ministério da Saúde, que são para a reforma do hospital, isso através de influência de parlamentares. Então a gente tem que buscar esses recursos por fora também. As parcerias são muito importantes, não só as questões formais, mas os contatos políticos também (E9).

É necessária a visão política, é necessário ter um trâmite político bom, interface com os políticos para você ter essa possibilidade de estar buscando melhorias não só com a Secretaria de Saúde, mas também em outros projetos de fora, projetos junto ao Ministério. Então é importante essa rede política (E12).

A gente se relaciona com todos eles, relacionamos com várias outras instituições de saúde e profissionais de saúde. Então nós temos contato com corpo de bombeiro, polícia militar, polícia civil, que já emprestaram aeronaves pra gente para ajudar na logística (E2).

A capacidade de articulação política é, desta forma, uma competência que deve estar presente na figura do diretor hospitalar. Ela é importante nas relações de cunho político e podem influenciar nas atividades e no volume de recursos aportado aos hospitais.

Durante as entrevistas todos os diretores realçaram que o conhecimento da administração pública é uma competência indispensável ao gestor de um hospital público. No início da entrevista, ao serem questionados sobre quais competências eles consideravam necessárias ao gestor hospitalar, sete dos 13 entrevistados citaram como primeira competência necessária o conhecimento das especificidades do setor público e os outro cinco diretores falaram sobre a importância do mesmo ao longo da entrevista.

Primeiro, é o conhecimento da administração pública, disponibilidade, abertura, no sentido da pessoa ser capaz de trabalhar no serviço público, que é completamente diferente do serviço privado. Diferente não é que tem que ser diferente, ele é diferente, a forma de tratar as pessoas, as leis trabalhistas, a forma da cobrança, o que você espera de resposta (E4).

Você tem que entender que estar em uma unidade de saúde pública do país, tem que entender primeiro de administração pública. Isso é fundamental, mesmo porque sem isso não funciona ( $E 7)$.

Conhecimentos básicos sobre administração e principalmente administração pública, conhecimento sobre o setor de saúde, conhecendo o setor de saúde ele tem que adequar os princípios da administração à área hospitalar, à saúde pública (E1).

Acho que tem que ter o conhecimento de direito administrativo que é importante para embasar as ações, as assinaturas de documentos, então para essa parte eu acho fundamental o direito administrativo (E8).

O limite da autonomia do gestor público também foi abordado pelos entrevistados. Eles relataram possuir certa autonomia, no entanto, em relação a questões consideradas maiores, como volume do orçamento, por exemplo, a autonomia é limitada. 
Ainda em relação à autonomia, uma especificidade do setor público muito lembrada pelos entrevistados foi a questão da contratação e demissão dos servidores públicos. Os diretores declararam que a falta de autonomia para contratar funcionários compromete o serviço, pois a falta de funcionários por si só gera grandes problemas. Ainda, a morosidade na realização de novos concursos públicos torna lento o processo de reposição do quadro de funcionários. Em relação à demissão, o problema gira em torno da estabilidade do funcionário público, que dificulta a demissão dos funcionários que não apresentam bom desempenho ou não cumprem as exigências do trabalho.

O conhecimento da administração pública também é percebido como uma competência necessária ao gestor público por Amaral (2006). A autora apresenta em seu trabalho as competências necessárias aos gestores públicos definidas pela Escola Nacional de Administração Pública (ENAP) e afirma que a administração pública é tradicionalmente orientada por regras rígidas e há pouco espaço para a experimentação.

\section{CONSIDERAÇÕES FINAIS}

Entre os papéis gerenciais propostos pelo Modelo de Quinn, o de diretor foi o que obteve mais destaque. A valorização do estabelecimento de metas e objetivos e o planejamento e organização contribuíram para esse resultado, que pode ser explicado como um reflexo da adoção do modelo de gestão pautado na busca pela eficiência, a partir da definição de metas e objetivos. E importante lembrar que saber ponderar os diferentes papéis, principalmente os que integram valores opostos, é uma necessidade do líder gerencial.

A administração pública brasileira enfrenta o desafio de melhorar a capacidade de gestão de suas instituições públicas. O aperfeiçoamento permanente dos gestores surge como uma necessidade para garantir a competitividade do país, promovendo um desenvolvimento mais igualitário e sustentável a partir da melhoria da qualidade do serviço prestado à população. É por essa razão que o oferecimento de cursos voltados para a área de gestão hospitalar e gestão pública aos diretores dos hospitais merece destaque entre os resultados obtidos pela pesquisa. O conhecimento da área de atuação deve compor as competências dos dirigentes. O conhecimento não leva necessariamente à ação, no entanto, a capacidade de ação dos gestores deve ser embasada no conhecimento formal, evitando, assim, a gestão amadora baseada em tentativas de erros e acertos.

O sistema público de saúde é alvo de fortes críticas por não atender às necessidades impostas pela população. Neste sentido, a percepção dos próprios diretores das instituições acerca da necessidade de uma gestão profissional representa um avanço na administração pública e pode contribuir para uma gestão hospitalar mais eficiente, eficaz e efetiva. Além disso, a existência da certificação profissional necessária para que os funcionários possam assumir os cargos de confiança relacionados à direção da instituição concede ao processo de nomeação um perfil mais profissional do que amador. A partir desses avanços espera-se que os hospitais públicos alcancem seus objetivos e, principalmente, respondam de forma humanitária e igualitária às necessidades da população.

A percepção inicial da pesquisa, referente à falta de capacitação dos diretores dos hospitais públicos de Belo Horizonte, foi rejeitada pela pesquisa a partir da constatação de que a competência e a qualificação são preocupações das instituições de saúde.

A principal contribuição deste trabalho foi o diagnóstico de que o modelo de Quinn mostra-se incompleto diante da realidade dos hospitais públicos de Minas Gerais. Desta forma, as competências capacidade de articulação política e conhecimento da administração pública e o papel político representam uma adequação do modelo à realidade estudada. As competências incorporadas ao modelo de Quinn mostram-se importantes nas relações de cunho político e influenciam nas atividades desenvolvidas nos hospitais, como a captação de recursos, por exemplo. 


\section{REFERÊNCIAS}

ACURCIO, F. A. Evolução histórica das políticas de saúde no Brasil. In: Heloisa Marcolino. (Org.). Projeto MultiplicaSUS: (Re)Descobrindo o SUS que temos para construirmos o SUS que queremos. 1 ed. Brasília: Ministério da Saúde, 2005, v. 1, p. 23-40.

AMARAL, H. K. Desenvolvimento de competência de servidores na administração pública. Revista do Serviço Público,v. 57, n. 4, p. 549-63, 2006. Disponível em: <http://www.searh.rn.gov.br/icongesprn/ artigos/artigo\%20-\%20RSP\%20-\%20compet_352ncia\%20dos\%20servidores_Helena.pdf >.

BARDIN, L. Análise de conteúdo. Lisboa: Edições 70, 2011.

BELO HORIZONTE. Sistema de Informações Organizacionais do Município. Lista dos Telefones. Unidade Selecionada e Unidades Subordinadas. Disponível em: <http://portal7.pbh.gov.br/Organograma/ estrutura.pbh?method=telTodos\&id=87>. Acesso em: 5 de dez. 2011.

BETIOLI, A. B. Introdução ao direito: lições de propedêutica jurídica. 3. ed. São Paulo: Letras \& Letras, 1995.

BRASIL. Hospital das Clínicas da Universidade Federal de Minas Gerais. Institucional. Organograma. Disponível em: <http://www.hc.ufmg.br/conheca_organograma.html >. Acesso em: 3 de dez. 2011.

MALHOTRA, N. Pesquisa de marketing: foco na decisão. 3. ed. São Paulo: Pearson, 2011.

MINAS GERAIS. Fundação Hospitalar do Estado de Minas Gerais. Atendimento Hospitalar. Disponível em: <http://www.fhemig.mg.gov.br/pt/atendimento-hospitalar>. Acesso em: 5 de out. 2011.

MORETTO NETO, Luis. SILVA, João José Cândido da, SCHIMITT, Valentina Gomes Haensel. Introdução à administração hospitalar. Florianópolis: Departamento de Ciências da Administração. UFSC, 2007.

PICCHIAI, D. Competências gerenciais - Casos de um hospital público. Cadernos Gestão Pública e Cidadania, v. 13, n. 52, São Paulo: 2008.

QUINN, R. et al. Competências Gerenciais: princípios e aplicações. Rio de Janeiro: Elsevier, 2003.

QUINN, R. Beyond Rational Management: Mastering the Paradoxes and Competing Demands of High Performace. San Francisco: Jossey-Bass, 1988. 